\title{
Quality of life of parents raising children with pervasive developmental disorders
}

\author{
Atsurou Yamada ${ }^{1 *+}$, Misuzu Kato $^{2}$, Miyoshi Suzuki ${ }^{3}$, Masako Suzuki ${ }^{1}$, Norio Watanabe ${ }^{1}$, Tatsuo Akechi ${ }^{1}$ and
} Toshi A Furukawa ${ }^{4}$

\begin{abstract}
Background: It has been reported that parents of children with pervasive developmental disorders (PDDs) face higher levels of stress. The aims of the present study were; (i) to evaluate the quality of life (QOL) of parents caring for their children with PDDs, and (ii) to explore the correlates of their QOL.

Methods: A consecutive sample of parents of children with PDDs aged 6 to 15 were approached. The MOS 36-item Short-Form Health Survey (SF-36) was used to measure the QOL of the parents by eight subscales and two summary measures. Parents' personality and marital relationships were assessed with the NEO Five Factor Inventory and the Intimate Bond Measure, respectively. We characterized the parents' SF-36 profiles in comparison with the national normative scores and explored variables which correlated with their summary measures.

Results: Participants were 147 mothers and 122 fathers of 158 children with PDDs. Mothers had significantly lower scores in the areas of Role Physical (RP) Social functioning (SF), General health perceptions (GH), Vitality (VT), Role emotional (RE) and Mental Health (MH) than those among the general female population. The maternal mental component summary (MCS) was also significantly lower, but maternal physical component summary (PCS) and paternal PCS and MCS scores were not lower. Maternal PCS and MCS scores were both significantly associated with the high Care and the low Control scores, but regarding fathers only the paternal PCS scores were significantly associated with the low Control scores. Maternal PCS and MCS and paternal MCS scores were significantly associated with the high Agreeableness scores and the low Neuroticism scores. Multiple regressions have shown that Neuroticism was significantly related to the low MCS scores of mothers and fathers. Next, Care was related to maternal high PCS, and Control was related to maternal low MCS and paternal low PCS.

Conclusions: The mothers of children with PDDs had lower QOL scores than those of the Japanese general population especially in mental domains. Impairment of the maternal QOL is significantly associated with the personality tendency of the parents and relationships with their partners.
\end{abstract}

\section{Background}

As the concept of the autistic spectrum becomes more wide spread, pervasive developmental disorders (PDDs) as a whole are receiving more attention than the narrowly defined autistic disorder per se. Because the prevalence of PDDs is 11.3 per 1000 children aged 8 years according to a recent report [1], it is far more prevalent than narrowly defined autistic disorders. As

\footnotetext{
*Correspondence: atsurou.yamada@mbr.nifty.com

${ }^{\dagger}$ Equal contributors

'Department of Psychiatry and Cognitive-Behavioral Medicine, Nagoya City University Graduate School of Medical Sciences, Mizuho-cho, Nagoya, Mizuho-ku, Japan

Full list of author information is available at the end of the article
}

PDDs become more common, the distress of rearing children with PDDs is receiving wider attention.

A number of studies have established that parents of children with autism face higher levels of stress than parents of children with other chronic diseases or intellectual disorders. The stress is higher among mothers than fathers [2-8], and mothers reported more anxiety [9] or more depression [10-13]. Recently the distress of the parents with PDDs including Asperger's disorder and any PDD not otherwise specified (PDDNOS) are receiving more attention. Many studies show these parents also have high distress [14]. It has been reported that parents of children with PDDs have impairment in their physical activity and social relationships and a

\section{Biomed Central}


worse overall perception of their quality of life (QOL) and health compared with parents of healthy children $[15,16]$. There is another study which suggested that the parents had poorer scores in all dimensions of health except physical health and had more psychological disorders [17]. Thus the parents of children with PDDs seem to have similar impairment in various domains of their QOL as the parents of children with autism.

The psychological adaptation of parents rearing children with PDDs has been recognized as being partly determined by the symptoms behavior problem [6,9], cognitive impairment [18],self-harm [2], sleep problems [19] and so on of the children, and partly determined by psychosocial factors [20-22]. On the other hand, social support has been identified as one of important moderators ameliorating the stress of parents of children with PDDs [23-27]. It has been reported that social support from the spouse in particular might be a predictor of decreasing complaints related with somatic symptoms and increasing feelings of accomplishment in parenting [28]. It is reported that parent who employed emotionfocused coping strategies had a greater disturbance in their QOL, and that parents to whom social support was less available employed such strategies [29].

In addition to this, personality characteristics such as locus of control and hardiness have also been identified as one of moderators which contribute to the well-being of mothers of children with PDDs [22-24,27,28].

There are many measures to assess the distress of parents. The QOL score is an important measure of individual well-being and it is considered a key variable in evaluating parents' adaptation to their children's disabilities [15-17,22,29-32]. For example, it is reported that a mother's feeling, history of chronic disease and religion were related to the QOL in mothers of children with autism [32]. Another previous study showed the parents of children with autism report a lower QOL and a greater level of child caring burden than the parents of children with attention deficit/hyperactivity disorders (ADHD) [31].

To the present, exactly what characteristics of the parents are related to the impairment of their QOL remains to be elucidated. Identifying these factors could contribute to better care for parents of PDD-affected children. The purpose of this study was to evaluate the QOL of parents caring for their children with PDDs and to explore their correlates.

In this report, we first assessed the QOL of parents caring for children with PDDs in the physical and psychological components of their QOL. Second, we explored the correlates with the impairment of QOL from the point of view of the relationship between mothers and fathers, and their personality characteristics.

\section{Methods}

We used data from our preceding study [14].

\section{Participants}

The details of the purposes and procedures of the study were explained to a consecutive sample of families of children with PDDs who visited the Outpatient Pediatric Neuropsychiatry Clinic of the Toyohashi Municipal Hospital, Japan, during the 3-month period from September to November 2006. The parents often had two or more target children. Because all of their children may affect their parents' QOL, we tried to obtain the data of all siblings if they were eligible and visiting our clinic.

Parents of children satisfying the following criteria were considered eligible for the study.

1) Children were of elementary school or junior high school age (6 to 15 years old);

2) Children were diagnosed as having autistic disorder, Asperger's disorder or PDD-NOS according to the DSM-IV diagnostic criteria [33] at our outpatient clinic;

3) Siblings of the children who satisfied 1) and 2) above and were visiting our outpatient clinic were also included even if they themselves did not visit the clinic during the period mentioned above.

We excluded:

1) Children for whom parents did not serve as the main care providers at home;

2) Children or parents whose mother tongue was not Japanese; and

3) Children with tuberous sclerosis.

After giving the necessary explanations at the outpatient clinic, we handed a questionnaire to those consenting to the study, requesting them to mail it back after completing it at home.

The study protocol was approved by the Ethics Committee of Toyohashi Municipal Hospital. Written informed consent was obtained from each of the parents who filled out and returned the self-report style questionnaire.

Data pertaining to the characteristics of individual children, such as age, sex, diagnosis, IQ (intelligence quotient) or DQ (developmental quotient), the characteristics of the autistic disorder and the time of the first visit to the clinic, were collected at the outpatient clinic. The diagnosis of the mental disorder was confirmed by the lead author (a child psychiatrist who had been engaged in child psychiatry for more than 7 years), based on the DSM-IV diagnostic criteria [34]. The IQ was measured with the Wechsler Intelligence Scale for 
Children-Third Edition (WISC-III) [35,36], and the DQ was measured with the Kyoto Scale of Psychological Development 2001 [37].

\section{Measures \\ The MOS 36-item Short-Form Health Survey (SF-36)}

SF-36 is a self-report questionnaire to assess general QOL. It contains 36 items that constitute 8 measures of Physical Functioning (PF), Role Physical (RP), Bodily Pain (BP), Social Functioning (SF), General Health Perceptions (GH), Vitality (VT), Role Emotional (RE), and Mental Health (MH). It also provides two summary measures, the Physical Component Summary (PCS) and the Mental Component Summary (MCS). The PCS refers to general factors of physical health, and it is associated with PF, RP, BP, GH and VT. The MCS refers to psychological health, and it is associated with $\mathrm{MH}, \mathrm{RE}, \mathrm{SF}, \mathrm{VT}$ and GH. The total result is shown in each of the 8 measures by a standard score which ranges from 0 to 100 , and the higher the score, the higher the QOL. The average and standard deviation of PCS and MCS scores of the general Japanese population are 50 and 10 respectively. The Japanese version has shown good reliability and validity in the general population of Japan $[38,39]$.

\section{Intimate Bond Measure (IBM)}

This measure is designed to evaluate the nature of the subject's relationship with their marital partner. It is a self-report measure for evaluation of two aspects of marital relationships (Care and Control), and is composed of 24 questions. The Care dimension reflects care expressed emotionally as well as physically, with constructs of warmth, consideration, affection and companionships. The Control dimension suggests domination, instructiveness, criticism, authoritarian attitudes and behaviors. The respondent selects one of the four answers $(3=$ yes, $2=$ somewhat yes, $1=$ relatively no, $0=$ absolutely no). Each aspect consists of 12 questions, therefore, the total score ranges from 0 to 36, and a high score means a tendency to Care or Control, respectively. The questions pertain to the recent situation, without specifying the period covered. The reliability and validity of this measure have been confirmed $[40,41]$.

\section{NEO Five Factor Inventory (NEO-FFI)}

The NEO-FFI is a concise measure of the five domains of personality according to the five-factor model. Twelve items are provided for each of the five dimensions of Neuroticism, Extraversion, Openness, Agreeableness, and Conscientiousness. Each item is answered on a five-point Likert scale $(0=$ strongly disagree, $1=$ disagree, $2=$ neutral, $3=$ agree, $4=$ strongly agree), so that each dimension is given a score from 0 to 48 and a high score means one has a higher tendency towards each personality. The
Japanese version has shown good reliability and validity in the general population of Japan [42].

\section{Brief demographic self-report questionnaire and family profiles}

The questionnaire included information about the age, occupation, education, and history of psychiatric treatment of the parents and the presence/absence of additional children with PDDs in the family.

\section{Analyses}

First, we calculated the mean values of the 8 subscales of SF-36 and compared them with those of age- and sexmatched general population subjects sampled in Japan by way of an unpaired $t$-test. The comparison group was sampled from 300 areas in Japan, stratified by its size of population, from each of which 15 people aged between 20 to 80 of age were randomly sampled. Finally the comparison group consisted of 1572 women and 1394 men [43]. We extracted the age- and sex-matched data from them. We also compared them between mothers and fathers by paired $t$-test. To evaluate the influence of number of rearing children with PDDs on PCS and MCS, we compared those scores of parents rearing one child with PDD and two or more children with PDDs. Next we explored variables which correlated with the PCS and MCS scores using Pearson's correlation coefficients. The independent variables we explored were the personality traits as measured by NEO-FFI and the husband-wife relationship as measured by IBM. Finally, a multiple regression analysis of the PCS and MCS scores of the mother and father was conducted by the forced entry method. We used SPSS for Windows 17.0 [44] for all data analyses. $p<.05$ was regarded as denoting statistical significance in all analyses.

\section{Results \\ Subjects}

We explained the study and gave questionnaires to a consecutive sample of 198 families. Responses were collected from 147 families (74.2\%) including 147 mothers and 122 fathers, covering 158 children. Table 1 shows the demographic data of the parents (Table 1). The 158 children consisted of 42 with autistic disorders ( 35 boys), 35 with Asperger's disorders (29 boys) and 81 with PDD-NOS (65 boys). One hundred twenty-four families including 124 mothers and 102 fathers had only one child diagnosed with PDD. The children ranged in age from 6 to 15 years and the mean age was 9 years 1 month ( $\mathrm{SD}=2$ years 6 months). The distribution of the IQ/DQ was as follows: Ninety children were over 70, 26 children were between 50 and 69, 18 children were between 35 and 49,7 children were between 20 and 34, and 6 children were less than 20 . 
Table 1 Demographic data of parents and children

\begin{tabular}{|c|c|c|}
\hline & Mother & Father \\
\hline Number & 147 & 122 \\
\hline Age(years) & $38.3(\mathrm{SD}=4.6)$ & $41.0(\mathrm{SD}=5.7)$ \\
\hline \multicolumn{3}{|l|}{ A parent-child relationship } \\
\hline Real & 147 & 121 \\
\hline Foster & 0 & 1 \\
\hline \multicolumn{3}{|l|}{ Marriage } \\
\hline Married & 138 & 122 \\
\hline Divorced & 9 & 0 \\
\hline \multicolumn{3}{|l|}{ Work } \\
\hline Housework or out of work & 74 & 1 \\
\hline Under 40 hours per week & 64 & 5 \\
\hline Over 40 hours per week & 9 & 116 \\
\hline \multicolumn{3}{|l|}{ Education } \\
\hline Up to junior high school & 3 & 6 \\
\hline High school & 77 & 66 \\
\hline Junior college or beyond & 67 & 50 \\
\hline \multicolumn{3}{|l|}{ Time spend with children } \\
\hline Almost never & 0 & 5 \\
\hline Less than one hour everyday & 1 & 17 \\
\hline $\begin{array}{l}\text { Less than one hour on weekdays } \\
\text { but more on weekends }\end{array}$ & 2 & 57 \\
\hline More than one hour everyday & 25 & 26 \\
\hline More than a few hours everyday & 119 & 17 \\
\hline \multicolumn{3}{|l|}{ Number of children with PDDs } \\
\hline One & 124 & 102 \\
\hline Two or more & 23 & 20 \\
\hline \multicolumn{3}{|l|}{ History of psychiatric treatment } \\
\hline Positive & 27 & 6 \\
\hline Negative & 120 & 116 \\
\hline
\end{tabular}

Abbreviations: PDD: pervasive developmental disorder; SD, standard deviation.

\section{QOL of parents}

Table 2 shows the scores of SF-36 (Table 2). The comparison groups consisted of 255 women aged from 30 to 39 , and 241 men aged from 40 to 49 who represented random samples from all areas in Japan mentioned above [43]. The mean scores of mothers were significantly lower than those of the general female population in six domains $(p<.01)$ especially in psychological areas. On the other hand, in the fathers, the mean scores were significantly lower only in 1 domain $(p<.05)$. The scores were lower among mothers than among fathers in 6 domains (all $p<.01$ ) especially in psychological areas.

The PCS and MCS average scores of 123 mothers with one child with PDD were 50.6 (Standard Deviation $[\mathrm{SD}]=6.7)$ and $43.3(\mathrm{SD}=11.8)$, and those of 23 mothers with two or more children with PDDs were 48.7 (SD = $8.0)$ and $41.0(\mathrm{SD}=12.7)$ respectively. There were no significant differences between the mothers with one child with PDD and two or more children with PDDs. The PCS and MCS average scores of 102 fathers with one child with PDD were $50.9(\mathrm{SD}=5.6)$ and 49.4 ( $\mathrm{SD}=7.9)$, and those of 20 fathers with two or more children with PDDs were $52.3(\mathrm{SD}=5.4)$ and $49.2(\mathrm{SD}=8.5)$ respectively. There were no significant differences, either.

\section{Correlates of QOL}

Table 3 shows the correlations between the PCS and MCS scores of SF-36 and the husband-wife relationship as measured with the IBM scores, the personality traits as measured with the NEO-FFI and other factors (Table 3). Maternal PCS and MCS scores were both significantly associated with the high Care scores and the low Control scores, but in the fathers only the PCS scores were associated with the low Control scores. Maternal PCS and MCS and paternal MCS scores were associated with the high Agreeableness scores and the low Neuroticism scores. In case of mothers, both the attitudes from their spouses and personal traits were significantly associated with physical and psychological QOL. In case of fathers, the attitudes from their spouses were associated with only physical QOL and personal traits were significantly associated with only psychological QOL.

In addition to this, the work time of mothers and fathers were significantly related to the high PCS scores of them respectively. Living with paternal grandparents was significantly related to the maternal high PCS scores. Parents working for more time tended to show higher physical QOL. The help from paternal grandparents may heighten the mothers' physical QOL. On the other hand, maternal education was associated with the high MCS scores. Mothers having an educational background may have resilience in the psychological domains.

Multiple regressions have shown that Neuroticism was significantly associated with the low psychological component scores of mothers and fathers. Next, Care was significantly associated with the high physical component scores of mothers, and Control was significantly associated with the low psychological component scores of mothers and the low physical component scores of fathers (Table 4).

The personal traits were important predictor of parental psychological QOL. On the other hand, the spouse's attitude was important predictor of paternal physical QOL and maternal psychological QOL.

\section{Discussion}

This is the first study that has thrown light on the relationships between the QOL of parents rearing children with PDDs and their psychosocial characteristics.

First, this study has revealed that mothers of children with PDDs had low QOL scores in several mental 
Table 2 The The MOS 36-item Short-Form Health Survey scores of parents and comparison with those of general population

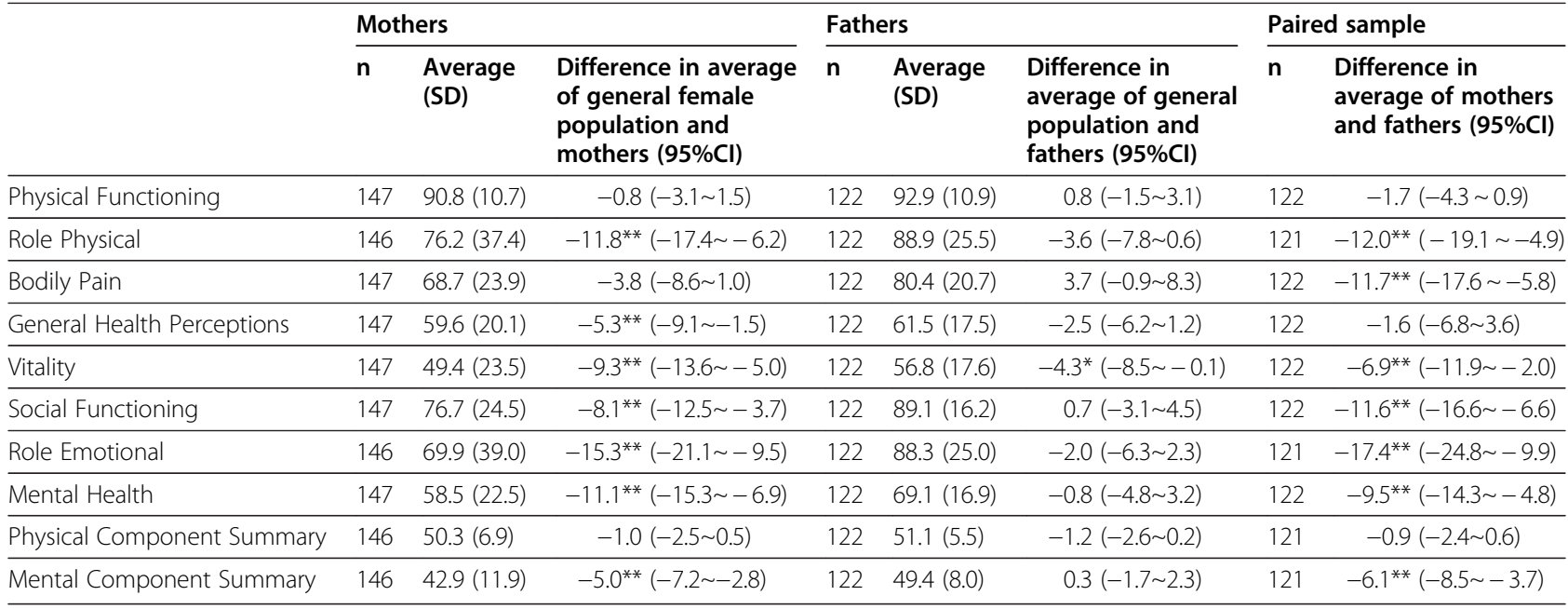

Abbreviations: $\mathrm{Cl}$, confidence interval; SD, Standard Deviation.

${ }^{*} p<.05 ;{ }^{* *} p<.01$.

domains. Almost all previous studies have shown impairment of QOL among such parents. There is a report that parents of children with autism spectrum disorders had significant poorer self-perceived health except for physical health dimensions [17], and our obtained results are consistent with the findings regarding mothers. According to the previous studies, the children's disabilities place a higher burden on the mothers among the parents of children with high functioning autism or Asperger's disease $[45,46]$, and there is a tendency for the mothers to suffer stronger impairment than the fathers in terms of the QOL $[15,16]$. Our results are largely in line with these previous reports.

The mothers of children with PDDs seem to have lower QOL than those of children with other chronic diseases because of their children's symptoms and behavior problems. PDDs seem to place greater burden on the parents in comparison with other developmental disorders. For example, the mothers of children with PDDs tend to have a lower QOL in the psychological domain than the mothers of children with mental retardation [15]. Parents of children with autism report a greater level of child caring burden, less frequent attendance of religious service, more school days missed, more repeated grades, less participation in activities/events, and less involvement in community services compared to parents of children with ADHD [31].

In this study, maternal QOL were significantly related to high Care scores and related to low Control scores in both physical and psychological areas. It has been generally indicated that social support is one of many important factors which contribute to the positive adaption of parents [21,23-25,28]. In particular, support from their partners seems to be associated with positive maternal outcomes $[11,27,47]$. The quality of the marriage has been reported to increase the ability to cope with the stress of parenting an autistic child [22], so that social support from their spouses contributes to positive maternal adaptation to a great extent. For example, single mothers appear to suffer from depression more easily than married mothers [12]. Some reports have suggested that the distress of mothers of PDD-affected children was correlated with perceived control by their spouses [14], expressed support from their spouses was the best predictor of quality of parenting [11], and mothers of autistic children expressed the need for additional support from their spouses [2]. Mothers should receive not only help but also supportive attitude, and should not be under psychological control from their husbands. According to one study, fathers were also much more likely to see themselves as being a reserve source of support for their wives [45].

Moreover, in this study, living with grandparents gave positive maternal QOL scores in physical domains. It is reported that greater family support was associated with increased optimism, and that in turn optimism was associated decreased depression and parenting stress [48]. Living with grandparents might help mothers and play an important role in maternal physical QOL.

Next we found that impairment of the mental QOL was strongly associated with the personality tendencies of the parents. There are rare reports about the association between QOL and personal traits, but a study exists which has reported that the QOL of patients with mood or anxiety disorders is not only determined by the disease or the current health but is also shaped by personality traits [49]. Our results showed that parents with higher Neuroticism scores seem to suffer from a poorer 
Table 3 Correlations between Maternal PCS and MCS scores and Intimate Bond Measure scores or NEO Five Factor Inventory scores

\begin{tabular}{|c|c|c|c|c|c|c|}
\hline & \multicolumn{3}{|c|}{ Mothers } & \multicolumn{3}{|c|}{ Fathers } \\
\hline & $\mathrm{n}$ & PCS & MCS & $\mathrm{n}$ & PCS & MCS \\
\hline \multicolumn{7}{|c|}{ Intimate Bond Measure scores ${ }^{a}$} \\
\hline Care by spouse & 137 & $.293^{* *}$ & $.178^{*}$ & 122 & .117 & -.018 \\
\hline Control by spouse & 137 & $-.173^{*}$ & $-.187^{*}$ & 122 & $-.278^{* *}$ & -.173 \\
\hline \multicolumn{7}{|c|}{ NEO Five Factor Inventory scores of mothers and fathers ${ }^{b}$} \\
\hline Neuroticism & 146 & $-.165^{*}$ & $-.468^{* *}$ & 122 & -.150 & $-.604^{* *}$ \\
\hline Extraversion & 146 & $.209^{*}$ & $.394^{* *}$ & 122 & -.041 & .176 \\
\hline Openness & 146 & -.152 & -.026 & 122 & .098 & .102 \\
\hline Agreeableness & 146 & $.170^{*}$ & $.268^{* *}$ & 122 & .002 & $.317^{* *}$ \\
\hline Conscientiousness & 146 & .084 & .030 & 122 & .035 & $.259^{* *}$ \\
\hline \multicolumn{7}{|l|}{ Time spend with children } \\
\hline Mothers & 146 & .012 & -.041 & 122 & .029 & -.085 \\
\hline Fathers & 121 & .133 & .119 & 122 & .065 & $.216^{*}$ \\
\hline \multicolumn{7}{|l|}{ Work time } \\
\hline Mothers & 146 & $.234^{* *}$ & .113 & 122 & -.085 & -.010 \\
\hline Fathers & 121 & -.136 & -.111 & 122 & $.258^{* *}$ & -.077 \\
\hline Education & 146 & -.058 & $-.183^{*}$ & 122 & .101 & .007 \\
\hline \multicolumn{7}{|l|}{ Living together } \\
\hline Paternal grandfather & 146 & $.196^{*}$ & .029 & 122 & .074 & -.131 \\
\hline Paternal grandmother & 146 & $.184^{*}$ & .092 & 122 & -.009 & -.094 \\
\hline Maternal grandfather & 146 & -.008 & -.025 & 122 & .029 & -.085 \\
\hline Maternal grandmother & 146 & -.002 & .036 & 122 & -.027 & .016 \\
\hline
\end{tabular}

QOL especially in psychological areas. The pattern of personality traits appears to dictate the patterns of the QOL. Knowing the parents' personality traits may therefore help us decide which interventions can be most successful among the parents.

There are few studies which have reported about the QOL of fathers. It is reported that maternal physical health was poorer than paternal physical health, but that self-related mental health did not differ between mothers and fathers of children with Asperger's disease or highfunctioning autism [16]. It is also reported that fathers of children with PDDs also showed statistically significant lower scores in the social relationship domain compared to fathers of normal developing children and in the psychological domain compared to fathers of children with cerebral palsy, but that mothers showed low scores in more domains than fathers [15]. Thus fathers seem to show less impairment in their QOL than mothers, but the causes are unknown. In this study, the paternal QOL scores were higher than mothers' QOL, but psychological domains were significantly associated with the attitude by spouse than those of the mothers.
There are some limitations in this study. First, this is a cross-sectional study, precluding any conclusions from being made with regard to causality. Second, we did not control for the parents' socioeconomic or marital status and number of rearing children when we compared our subjects with the general population, because such information was not available for the normative dataset of SF-36. In an analysis of the QOL, these issues are regarded as limitations because they have been suggested as factors associated with the cores of SF-36 in preceding reports [15]. Third, there might be a sampling bias because all the subjects were parents whose children came to the hospital. One population study reported that mothers of children with autistic disorders showed remarkable strengths in the parent-child relationship and coping with parenting tasks regardless of high stress and poor mental health [20]. Future research should be performed on the general population basis.

Taken together, the results of the present study suggest that we may need to support parents, especially mothers, of children with PDDs in all the aspects of their lives that have been shown to correlate with their QOL. 
Table 4 The correlations between Intimate Bond Measure scores, NEO Five Factor Inventory scores and Parental PCS and MCS scores

\begin{tabular}{|c|c|c|c|}
\hline & $\begin{array}{l}\text { Standardized } \\
\text { Coefficients }(\beta)\end{array}$ & $T$ & Adjusted $\mathrm{R}^{2}$ \\
\hline Maternal PCS scores & & $6.684^{* *}$ & .141 \\
\hline Care & .238 & $2.734^{* *}$ & \\
\hline Control & -.092 & -1.059 & \\
\hline Neuroticism & -.011 & -.116 & \\
\hline Extraversion & .086 & .862 & \\
\hline Agreeableness & .067 & .735 & \\
\hline Work time of mothers & .156 & 1.825 & \\
\hline $\begin{array}{l}\text { Living with paternal } \\
\text { grandfather }\end{array}$ & .177 & 1.217 & \\
\hline $\begin{array}{l}\text { Living with paternal } \\
\text { grandmother }\end{array}$ & .005 & .031 & \\
\hline Maternal MCS scores & & $4.495^{* *}$ & .273 \\
\hline Care & .017 & .215 & \\
\hline Control & -.174 & $-2.195^{*}$ & \\
\hline Neuroticism & -.321 & $-3.646^{* *}$ & \\
\hline Extraversion & .219 & $2.512^{*}$ & \\
\hline Agreeableness & .022 & .258 & \\
\hline Education of mothers & .117 & 1.539 & \\
\hline Paternal PCS scores & & $7.319^{* *}$ & .123 \\
\hline Control & -.266 & $-3.121^{* *}$ & \\
\hline Work time of fathers & .245 & $2.878^{* *}$ & \\
\hline Paternal MCS scores & & $8.802^{* *}$ & .402 \\
\hline Neuroticism & -.549 & $-6.776^{* *}$ & \\
\hline Agreeableness & .088 & 1.143 & \\
\hline Conscientiousness & .071 & .953 & \\
\hline $\begin{array}{l}\text { Time fathers spend } \\
\text { with children }\end{array}$ & .205 & $2.884^{* *}$ & \\
\hline
\end{tabular}

Abbreviations: PCS, Physical Component Summary; MCS, Mental Component Summary.

${ }^{*} p<.05 ;{ }^{* *} p<.01$.

Social support strategies including the spousal support have been identified as the important factor for these mothers. We would need further studies with a similar design to replicate this finding not only in the treatment-seeking subjects but also in the communitydwelling subjects and their families.

\section{Conclusions}

Not only the mothers of children with autistic disorder but also mothers of children with other PDDs had lower QOL scores than fathers, especially in the mental domains. Impairment of maternal QOL is significantly associated with the personality tendency of the mothers and relationships with their partners. Clinicians can deliver better service by paying appropriate attention to the QOL of parents whose children have autistic disorders or other PDDs.
Competing interests

The authors declare that they have no competing interests.

\section{Authors' contributions}

All authors have contributed essential parts to the manuscript and are entirely responsible for its scientific content. AY and TAF planned the study. AY, MiS and MK carried out the investigation. AY and TAF analyzed the all data. MaS, NW, TA and TAF critically commented on the draft manuscript. All authors have read and approved the final version of the manuscript.

\section{Acknowledgements \\ Statistical expert: None.}

Financial support: None.

\section{Author details}

${ }^{1}$ Department of Psychiatry and Cognitive-Behavioral Medicine, Nagoya City University Graduate School of Medical Sciences, Mizuho-cho, Nagoya, Mizuho-ku, Japan. ${ }^{2}$ Children's Mental and Physical Development Center, 100 Aza Nakahara, Nakano-Cho, Toyohashi, Aichi, Japan. ${ }^{3}$ Iwanishi nursery school, 1-104 Kitahara Takashi-Cho, Toyohashi, Aichi, Japan. ${ }^{4}$ Department of Health Promotion and Human Behavior (Cognitive-Behavioral Medicine), Kyoto University Graduate School of Medicine/School of Public Health, Yoshida Konoe-cho, Kyoto, Sakyo-ku, Japan.

Received: 1 November 2011 Accepted: 23 May 2012

Published: 20 August 2012

\section{References}

1. Wingate M, Mulvihill B, Kirby R, Pettygrove S, Cunniff C, Meaney F, Schulz E, Miller L, Robinson C, Quintana G, et al: Prevalence of autism spectrum disorders - autism and developmental disabilities monitoring network, 14 sites, United States. MMWR Surveill Summ 2008, 61(3):1-19.

2. Konstantareas MM, Homatidis S: Assessing child symptom severity and stress in parents of autistic children. J Child Psychol Psychiatry 1989, 30(3):459-470.

3. Konstantareas MM, Homatidis S: Mothers' and fathers' self-report of involvement with autistic, mentally delayed, and normal children. Journal of Marriage and the family 1992, 54:153-164.

4. Moes D, Koegel RL, Schreibman L, Loos LM: Stress profiles for mothers and fathers of children with autism. Psychol Rep 1992, 71(3 Pt 2):1272-1274.

5. Dumas JE, Wolf LC, Fisman SN, Culligan A: Parenting stress, child behavior problems, and dysphoria in parents of children with autism, Down syndrome, behavior disorders, and normal development. Exceptionality 1991, 2:97-110.

6. Freeman NL, Perry A, Factor DC: Child behaviours as stressors: replicating and extending the use of the CARS as a measure of stress: a research note. J Child Psychol Psychiatry 1991, 32(6):1025-1030.

7. Holroyd J: The Questionnaire on Resources and Stress: An instrument to measure family response to a handicapped family member. J Community Psychol 1974, 2:92-94.

8. Wolf LC, Noh S, Fisman SN, Speechley M: Psychological effects of parenting stress on parents of autistic children. J Autism Dev Disord 1989, 19(1):157-166.

9. Hastings RP: Child behaviour problems and partner mental health as correlates of stress in mothers and fathers of children with autism. $J$ Intellect Disabil Res 2003, 47(Pt 4-5):231-237.

10. Hastings RP, Kovshoff $H$, Ward NJ, Degli Espinosa F, Brown T, Remington B: Systems analysis of stress and positive perceptions in mothers and fathers of pre-school children with autism. J Autism Dev Disord 2005, 35(5):635-644.

11. Bristol MM, Gallagher JJ, Schopler E: Mothers and fathers of young developmentally disabled and nondisabled boys: adaptation and spousal support. Dev Psychol 1988, 24:441-451.

12. Olsson MB, Hwang CP: Depression in mothers and fathers of children with intellectual disability. J Intellect Disabil Res 2001, 45(Pt 6):535-543.

13. Gray DE: Psycho-sdocial well-being among the parents of children with autism. Australia and New Zealand Journal of Developmental Disabiltities 1992, 18(2):83-93.

14. Yamada A, Suzuki M, Kato M, Suzuki M, Tanaka S, Shindo T, Taketani K, Akechi T, Furukawa TA: Emotional distress and its correlates among 
parents of children with pervasive developmental disorders. Psychiatry Clin Neurosci 2007, 61(6):651-657.

15. Mugno D, Ruta L, D'Arrigo VG, Mazzone L: Impairment of quality of life in parents of children and adolescents with pervasive developmental disorder. Health and quality of life outcomes 2007, 5:22.

16. Allik H, Larsson JO, Smedje H: Health-related quality of life in parents of school-age children with Asperger Syndrome or High-Functioning Autism. Health and quality of life outcomes 2006, 4:1.

17. Benjak T, Vuletic Mavrinac G, Pavic Simetin I: Comparative study on selfperceived health of parents of children with autism spectrum disorders and parents of non-disabled children in Croatia. Croat Med J 2009, 50(4):403-409.

18. Koegel RL, Schreibman L, Loos LM, Dirlich-Wilhelm H, Dunlap G, Robbins FR, Plienis AJ: Consistent stress profiles in mothers of children with autism. $J$ Autism Dev Disord 1992, 22(2):205-216.

19. Doo S, Wing YK: Sleep problems of children with pervasive developmental disorders: correlation with parental stress. Dev Med Child Neurol 2006, 48(8):650-655

20. Montes $G$, Halterman JS: Psychological functioning and coping among mothers of children with autism: a population-based study. Pediatrics 2007, 119(5):e1040-e1046.

21. Weiss SJ: Stressors experienced by family caregivers of children with pervasive developmental disorders. Child Psychiatry Hum Dev 1991, 21(3):203-216.

22. Siman-Tov A, Kaniel S: Stress and Personal Resource as Predictors of the Adjustment of Parents to Autistic Children: A Multivariate Model. J Autism Dev Disord 2011, 41(7):879-890.

23. Dunn ME, Burbine T, Bowers CA, Tantleff-Dunn S: Moderators of stress in parents of children with autism. Community Ment Health J 2001 37(1):39-52.

24. Gill MJ, Harris SL: Hardiness and social support as predictors of psychological discomfort in mothers of children with autism. J Autism Dev Disord 1991, 21(4):407-416.

25. Factor DC, Perry A, Freeman N: Stress, social support, and respite care use in families with autistic children. J Autism Dev Disord 1990, 20(1):139-146

26. Pakenham Kl, Samios C, Sofronoff K: Adjustment in mothers of children with Asperger syndrome: an application of the double ABCX model of family adjustment. Autism 2005, 9(2):191-212.

27. Ekas NV, Lickenbrock DM, Whitman TL: Optimism, social support, and wellbeing in mothers of children with autism spectrum disorder. J Autism Dev Disord 2010, 40(10):1274-1284.

28. Weiss MJ: Hardiness and social support as predictors of stress in mothers of typical children, children with autism, and children with mental retardation. Autism 2002, 6(1):115-130.

29. Cappe E, Wolff M, Bobet R, Adrien JL: Quality of life: a key variable to consider in the evaluation of adjustment in parents of children with autism spectrum disorders and in the development of relevant support and assistance programmes. Qual Life Res 2011, 20(8):1279-1294.

30. Shu BC, Lung FW: The effect of support group on the mental health and quality of life for mothers with autistic children. J Intellect Disabil Res 2005, 49(Pt 1):47-53.

31. Lee LC, Harrington RA, Louie BB, Newschaffer CJ: Children with autism: quality of life and parental concerns. J Autism Dev Disord 2008, 38(6):1147-1160.

32. Shu BC: Quality of life of family caregivers of children with autism: The mother's perspective. Autism 2009, 13(1):81-91.

33. American Psychiatric Asoociation: Diagnostic and statistics manual of mental disorders. 4th edition. Washington, DC: Author; 1994.

34. American Psychiatric Association: Diagnostic and statistics manual of mental disorders. 4th edition. Washington, DC: DSM-IV; 1994.

35. Wechsler D: Manual for the Wechsler Intelligence Scale for Children-Third Edition. San Antonio, TX: The Pshycological Corporation; 1991.

36. Wechsler D: The Japanese version of manual for the Wechsler Intelligence Scale for Children-Third Edition. Tokyo: Nihon Bunka Kagakusha; 1998.

37. Ikuzawa M, Matsushita H, Nakase A: the Manual for Kyoto Scale Psychological Development 2001. Kyoto: Kyoto International Social Welfare Exchange Centre; 2002.

38. Fukuhara S, Bito S, Green J, Hsiao A, Kurokawa K: Translation, adaptation, and validation of the SF-36 Health Survey for use in Japan. J Clin Epidemiol 1998, 51(11):1037-1044
39. Fukuhara S, Ware JE Jr, Kosinski M, Wada S, Gandek B: Psychometric and clinical tests of validity of the Japanese SF-36 Health Survey. J Clin Epidemiol 1998, 51(11):1045-1053.

40. Wilhelm K, Parker G: The development of a measure of intimate bonds. Psychol Med 1988, 18(1):225-234.

41. Furukawa TA, Hori S, Azuma H, Nakano Y, Oshima M, Kitamura T, Ogasawara Sugiura M, Aoki K: Parents, personality or partner? Correlates of marital relationships. Soc Psychiatry Psychiatr Epidemiol 2002, 37(4):164-168.

42. Yoshimura K, Ono Y, Nakamura K, Nathan JH, Suzuki K: Validation of the Japanese version of the NEO Five-Factor Inventory in a large community sample. Psychol Rep 2001, 88(2):443-449.

43. Fukuhara S, Suzukamo Y: Manual of SF-36v2 Japanese version. Kyoto: Institute for Health Outcomes \& Process Evaluation Research; 2004

44. SPSS Inc: SPSS for Windows Version 17.0. SPSS for Windows Version 17.0 edition. Chicago, IL: SPSS Inc: 2008.

45. Gray DE: Gender and coping: the parents of children with high functioning autism. Soc Sci Med 2003, 56(3):631-642

46. Little L: Differences in stress and coping for mothers and fathers of children with Asperger's syndrome and nonverbal learning disorders. Pediatr Nurs 2002, 28(6):565-570.

47. Bristol MM: Mothers of children with autism or communication disorders: successful adaptation and the double ABCX model. J Autism Dev Disord 1987, 17(4):469-486.

48. Ekas NV, Whitman TL, Shivers C: Religiosity, spirituality, and socioemotional functioning in mothers of children with autism spectrum disorder. J Autism Dev Disord 2009, 39(5):706-719.

49. van Straten A, Cuijpers P, van Zuuren FJ, Smits N, Donker M: Personality traits and health-related quality of life in patients with mood and anxiety disorders. Qual Life Res 2007, 16(1):1-8.

doi:10.1186/1471-244X-12-119

Cite this article as: Yamada et al:: Quality of life of parents raising children with pervasive developmental disorders. BMC Psychiatry 2012 12:119.

\section{Submit your next manuscript to BioMed Central and take full advantage of:}

- Convenient online submission

- Thorough peer review

- No space constraints or color figure charges

- Immediate publication on acceptance

- Inclusion in PubMed, CAS, Scopus and Google Scholar

- Research which is freely available for redistribution 